\title{
MEDIUMSHIP AND THE ECONOMY OF LUCK AND FATE: CONTEMPORARY CHINESE BELIEF TRENDS BEHIND THE FILMIC FOLKLORE
}

\author{
Huai Bao
}

\begin{abstract}
This study explores the pen spirit, a mediumistic game simplified out of fuji, which is shown in a number of popular horror films in the People's Republic of China (PRC). While Chinese literary works in the past often made reference to fuji as an ancient Chinese mediumistic ritual, the communist government has suppressed expressions on the supernatural in publications and official media, but not in films - at least not in the popular pen spirit series. What is a pen spirit? Why is it so popular in China, especially among Chinese youngsters? Is there a 'cultural obsession' among the Chinese with fate, luck, and divination? This study seeks to discover the evolution of the pen spirit and the socio-cultural psychological dimensions behind the phenomenon.
\end{abstract}

Keywords: divination, economy of luck and fate, filmic folklore, fuji, mediumship, supernatural

\section{INTRODUCTION}

In the past few years, a number of low-budget pen spirit thrillers have been released in the PRC with great box office outcome. These films may be classified as filmic folklore, a term coined by Juwen Zhang, which is defined as "a folklore or folklore-like performance that is represented, created, or hybridized in fictional film" (2005: 267). These films have been released and publicized by the media in the PRC largely due to their filmic folkloric nature. A 2014 news report on the lawsuit between some Beijing-based film production companies brought attention to the popularity of horror films featuring the pen spirit - a popular form of mediumship in China similar to the Ouija board in the West (more on Ouija board see Brunvand 1998 [1996]: 534). While both the plaintiff and the defendants have produced horror films featuring the pen spirit, the former sued the latter for engaging in an unfair competition, in which the latter used the Chinese word, 笔仙 (bixian, pen spirit), in its Chinese language title for the series titled Death Is Here (《笔仙惊魂》), following the success of the plaintiff's South Korean film (2004), which also used the same words in the Chinese 
language title of its pen spirit horror franchise, Bunshinsaba (분신사바). The news report claims:

Though this is not the first case of a company being accused of producing a film that shares a similar title of a more successful one to attract audiences [---] this is the first time such a case has been brought to court. (Ma 2014)

Notably, the latter did become successful, as it ranked number ten on the top ten Chinese box office records in $2012 .{ }^{1}$ The success of such films - at least in terms of frequent media coverage - has triggered my interest in examining how popular culture reflects the contemporary Chinese society through the lens of its past and present belief traditions and trends.

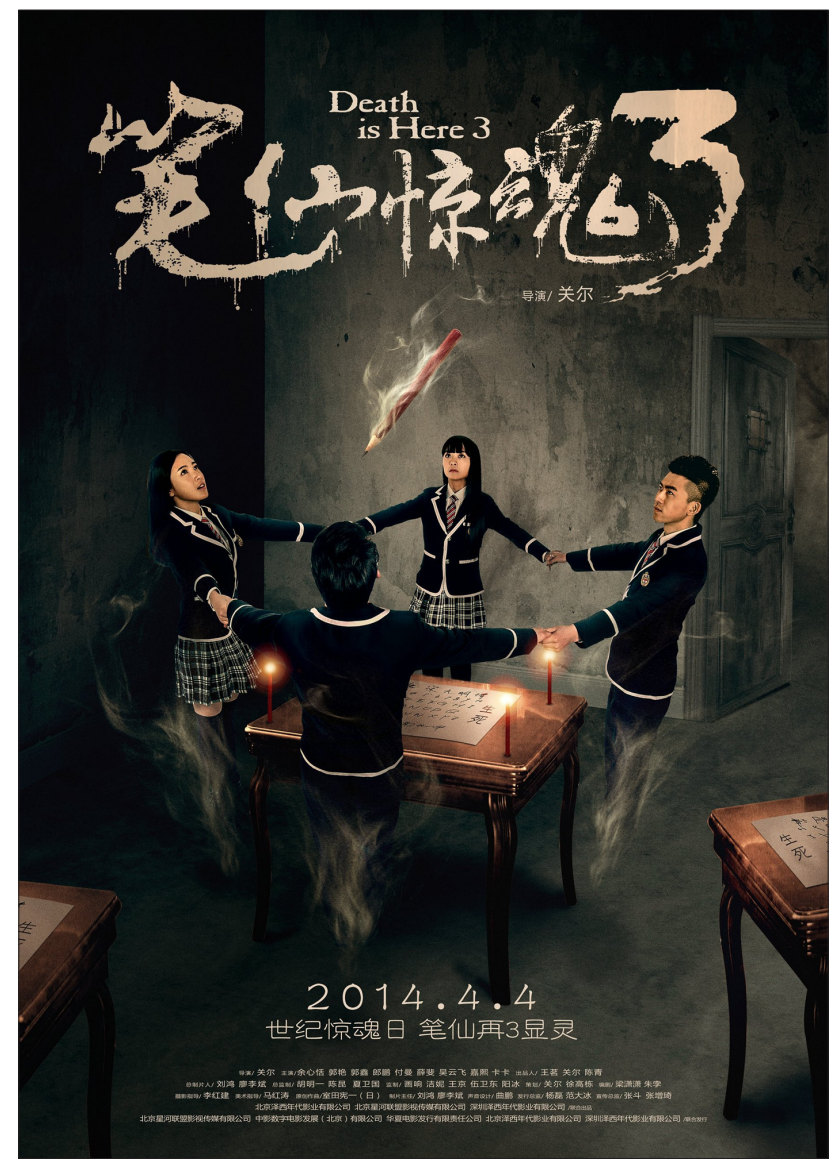

Figure 1. Poster of the film "Death is Here 3", 2014 (PRC public domain http://www.publicdomainpictures.net). 


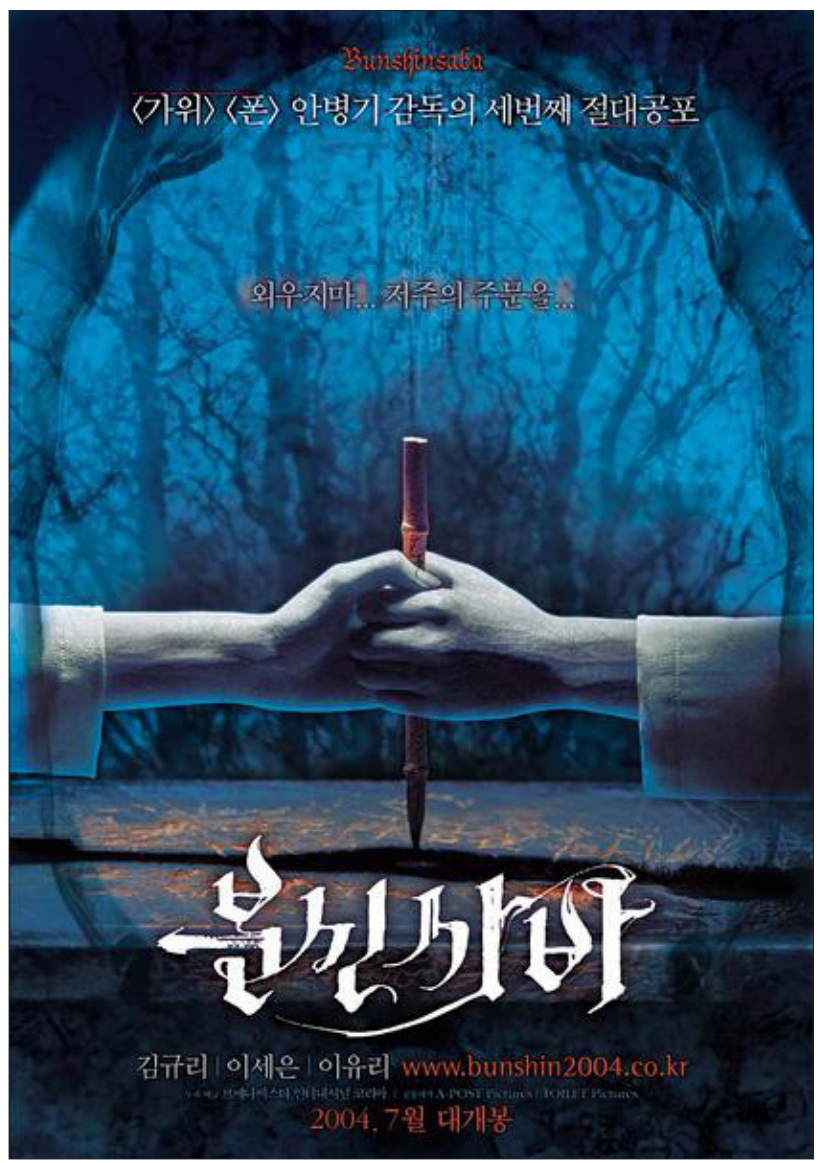

Figure 2. Poster of the film "Bushinsaba", 2004

(PRC public domain http:/ / www.publicdomainpictures.net).

\section{MEDIUMSHIP, LAWS, AND FILMS: \\ THE CONTEXT OF THE PEN SPIRIT}

Since 2010, when I began to write my second book, Change Destiny ( 《改命》), which was subsequently published by the New World Press in Beijing in 2012, I have interviewed about 200 individual $\mathrm{s}^{2}$ in the $\mathrm{PRC}$ regarding divination and mediumship, which have traditionally been very common topics in Chinese folklore (more on mediumship traditions in China see Clart 2003). I examined the connection between the increasing popularity of the pen spirit among youngsters and the successful cinematic representation of the pen spirit. While pre-modern Chinese literary works often refer to fuji (扶乩) ${ }^{3}$ as an ancient 
Chinese mediumistic ritual, in which a human being receives guidance from spirits and conveys messages from above, the government of the PRC has suppressed expressions of mediumship in publications and mainstream media. In fact, according to the editors, my most recent book, Change Destiny, was banned shortly after its launch in mainland China because certain chapters reviewed the historical facts and testimonials of fuji, the pen spirit, and the Ouija board, as well as paranormal phenomena in religious scenes. I was informed that these topics were taboo in the predominantly atheist social environment governed by the Communist Party of China (CPC). Cinema and fiction receive much less restriction on the governmental level, largely because the folkloric representation of mediumship reduces their realistic implications. Many 'hidden rules', which are not written on paper, have been instrumental in governing, scrutinizing and orientating ideological production in an attempt to maintain social stability. To avoid such hidden rules means restriction on one's creativity. The government of the PRC has green-lighted the horror film genre in the recent years, although with certain restrictions on the horror elements and content (there is a motion picture rating system in the PRC). Consequently, this genre appears to be not only a place "where the magical worldview [---] could exist without being questioned in a secular context" (Koven 2003: 182), but also a place where there are fewer political risks.

\section{PEN SPIRIT AS A GAME AND A RITUAL}

Traditionally, fuji has been a popular topic in Chinese folklore (more about the tradition of fuji beliefs see Wei-pang 1942). Treated as a simplified version of fuji, the pen spirit is a modern popular game-like ritual in China, especially among youngsters. It is believed that through this ritual spirits can be invited to answer questions posed by the players. Compared to fuji, the pen spirit is widely known among the youngsters largely because this simplified form has abandoned the use of complicated tools, such as the suspended sieve and tray, stick, sand or incense ashes, and knowledge of the Five Elements of the yinand-yang philosophical system, ${ }^{4}$ as well as the Chinese sexagenary cycle known as Stems-and-Branches, a cycle of sixty terms used for recording days or years. Moreover, the game does not require the players to possess abilities of extrasensory perception. Of the 30 students and recent university graduates that I randomly chose online and interviewed in the PRC, all had heard of the pen spirit and many had seen or heard about pen spirit films. All the interviewees had played or had friends who had played or observed others play the game. 


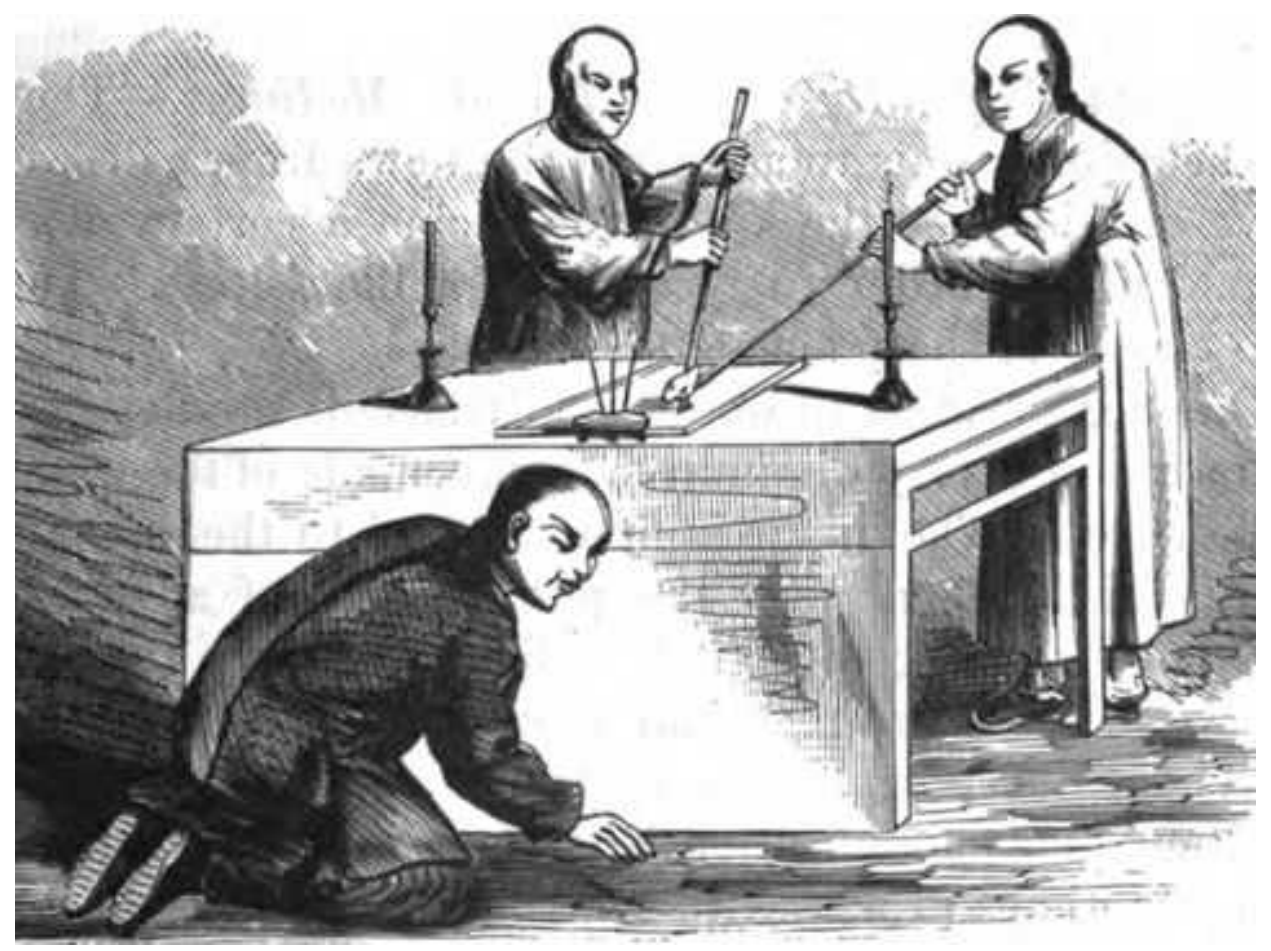

Figure 3. Fuji, an ancient Chinese mediumistic ritual (PRC public domain http: / / www.publicdomainpictures.net).

The game is played in a quiet and dark room with only dim candlelight on, usually around midnight, in order to keep the noise of outdoor traffic to a minimum. The candlelight helps to create a hypnotic atmosphere, which may bring the game players into a concentrated state of mind. Oftentimes, the players will also burn incense to reduce the oxygen in the air. The wispy smoke arising from the burning incense and the fragrant odor are believed to be contributive to developing a hypnotic state. To play the pen spirit game, the players will first write down on a large piece of paper numbers from 0 to 9 , as well as 'yes' and 'no', 'male' and 'female', and such descriptive words as 'wealthy', 'impoverished', 'famous', 'healthy', 'powerful', or any prepared short answers. Given the logographic nature of the Chinese language and the large number of Chinese characters, the prepared answers are unable to offer more information than the Ouija board, which can create any words, phrases, or even sentences using the 26 alphabetic letters. This has made the 'talking board' of the pen spirit look more complicated than the Ouija board, but in nature there is not much difference between the two. 


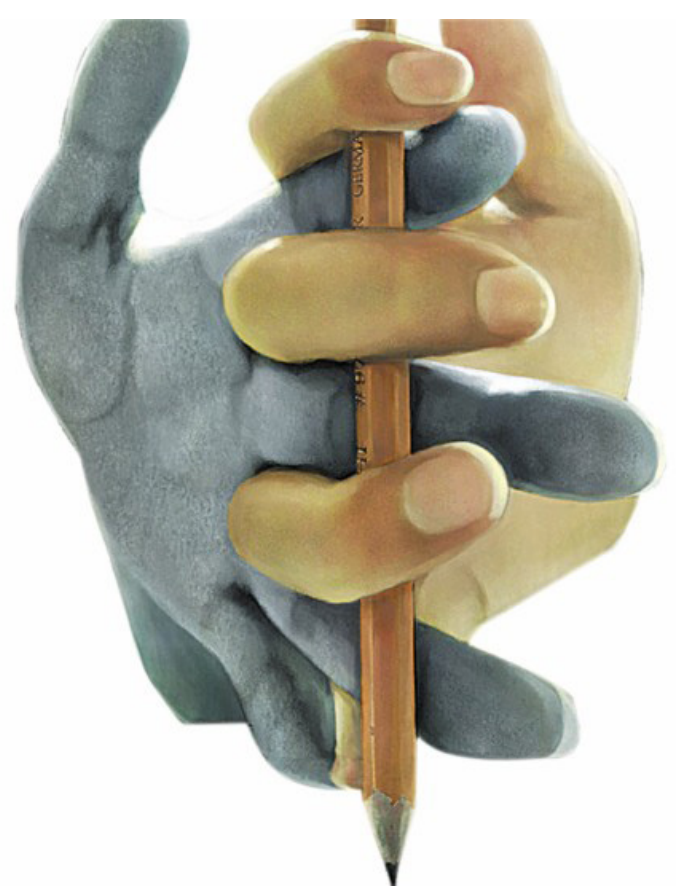

Figure 4. Hand position for the pen spirit game (PRC public domain http: / / www.publicdomainpictures.net).

For the pen spirit two players will hook their right hands together, with fingers crossed with each other, holding a pen gently in between the two hands perpendicular to the table surface. The players try not to touch the table surface with their elbows throughout the game. When the players are ready, they will chant, "Pen spirit, pen spirit, please come now and we need your advice!" There are different versions of the chant; some sound more formal than others. It normally takes a few minutes before the hands begin to move, and while the hands are moving, the pen being held in between will move on the piece of paper. To begin the session, the players will ask, "Are you here, pen spirit? If yes, please answer us." Then the players may find that their hands as well as the pen will slowly move to 'yes', around which character the pen will draw a circle. In most cases, the players are astonished, as both parties deny that it is his or her hand that is taking the lead in the movement; rather, they both think that they are simply following the other party. By following this ritual, they may ask anything they want to know about, and the pen spirit will provide an answer. The players 
will have to keep their questions simple. Usually a yes-no question is the best. When they decide to stop the game, they will send the 'spirit' away politely. During the course of my interviews, I have collected a mélange of 'miracle' stories, but I am not able to verify those allegedly 'accurate' predictions by the pen spirit. As for the credibility of the answers, most of these young players are not skeptical, emphasizing that the more faith one has in the existence of 'spirits', the more accurate responses one may receive. There are also rumors about pen spirit game addiction as well as players being possessed by an evil pen spirit after performing it. Many of the descriptions of their own practices are identical with the depictions in the pen spirit horror films.

Similar to the pen spirit, the equally popular dish spirit replaces the pen with a bowl or a small dish placed upside down on a large piece of paper spread out on a table, with numbers and characters written on it. Like the Ouija board, it has to involve more than two players. The bowl or a small dish, with an arrow marked on one side, functions as a planchette, and the paper as the board. ${ }^{5}$

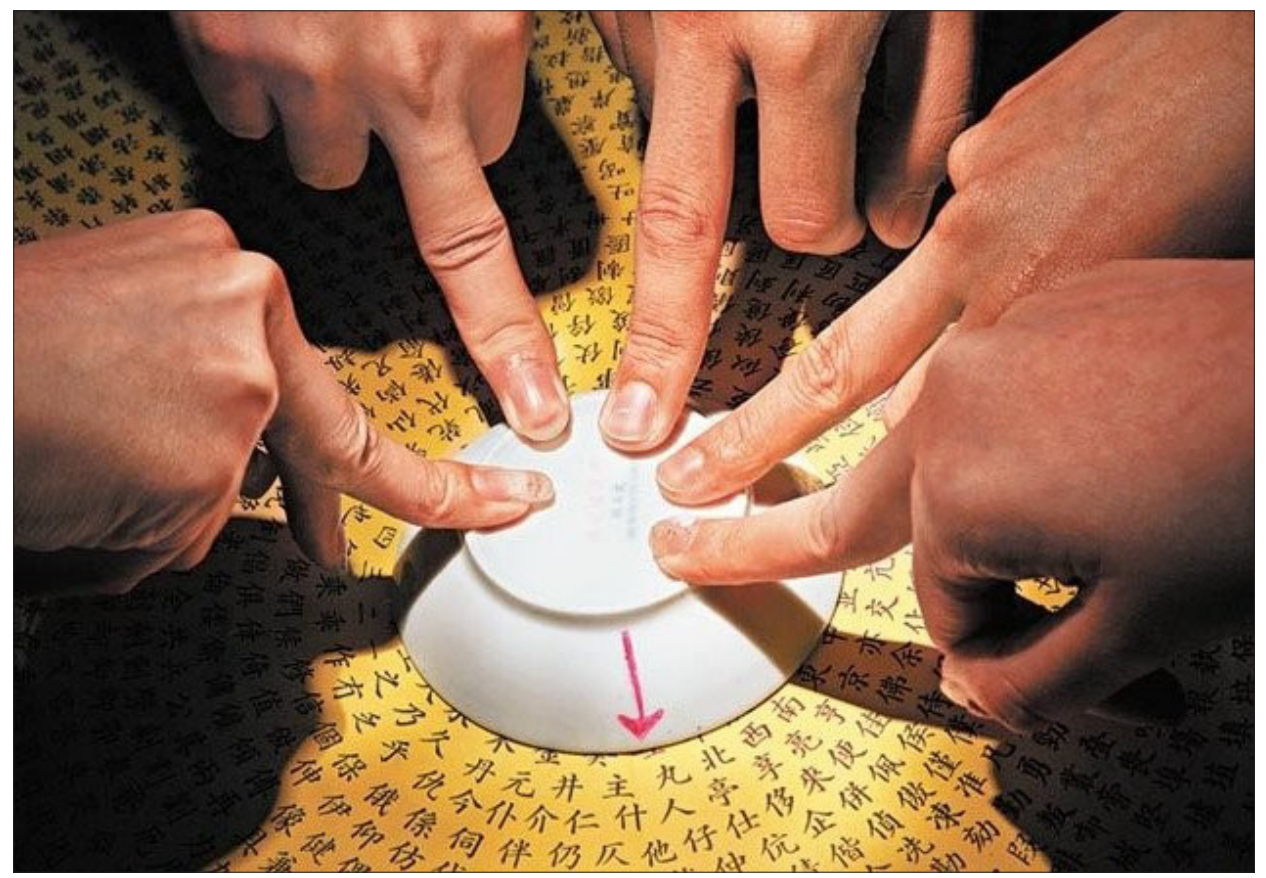

Figure 5. The dish spirit game

(PRC public domain http:/ / www.publicdomainpictures.net). 


\section{FATE, LUCK, AND MEDIUMSHIP IN CHINA: CULTURAL AND RELIGIOUS BACKGROUND}

Psychologists have concluded that the Ouija board response, as well as table turning, dowsing, and pendulum use, may be explained in terms of ideomotor actions - movements or behaviours that are unconsciously initiated (Gauchou \& Rensinka \& Fels 2012: 976-982). Similar to the Ouija game, in the pen spirit game, the pen serves as the movable indicator - the planchette. Players ask a question, holding the pen with crossed hands, and then follow the pen as it moves about on a piece of paper with prepared answers. Small hand movements are transferred to the pen. When one player lifts up his/her arm in mid-air, blindfolded in particular, he/she can hardly keep his/her arm steady without slightly moving. Thus, the small movements seem autonomous. When one person moves unconsciously, the other player is convinced that it is the other player or the pen spirit that is moving. In this sense, each party becomes an accomplice of the other. In this study, I do not intend to focus on how the game players move. What I find more interesting in this popular game among youngsters in the PRC, and the cinematic representations of this game, is why so many people believe and engage in the game. In addition, as I have observed over the years, average Chinese people seem to have a long-time cultural 'obsession' with divination, which is associated with their "obsession with fate and luck" (Sangren 2012: 117ff.). When I was working on Change Destiny between 2010 and 2012, I interviewed approximately 200 individuals of different age groups in the PRC regarding divination and mediumship. Most teenager respondents knew about or had practiced the pen spirit game in order to learn about their future, yet $90 \%$ of the adult respondents had been involved in at least one form of various divinations (typically, they would visit an I-Ching master, a Tibetan lama, or a psychic). Their oral accounts have been recorded in the book (Bao 2012).

The discourse surrounding fate had existed in the Chinese thought long before Buddhism spread to China, yet Buddhism once again introduced the concept of fatalism to the Chinese (Eberhard 1966: 149). Although orthodox Buddhist doctrines discourage divination, the concept of fatalism based on the principle of cause and effect, which has profoundly shaped the collective unconscious of the Chinese, provides a theoretically legitimate and practically necessary basis for divination, especially under the circumstance where the subject feels that 'God plays dice' and that fate is out of control. In the course of my research, my informants who have cross-cultural and/or transnational experiences have reaffirmed this observation: While a large percentage of their associates in the PRC and/or in the Chinese communities in Canada have 
been to a psychic or involved in self-service divination at least once in the past year, Westerners are more likely to be skeptical about divination or claim that they do not believe in it, or do not feel the need to go for it. One informant of Chinese origin who lives in Toronto, Canada, says, "I've been to this psychic medium regularly every year for the past seven years. She is Iranian, and lives in a White neighborhood, but most of her clients I have seen at her house are Chinese; only a few are White Canadians." Here, I do not intend to enter into an argument on statistical truths, but I want to reaffirm that, compared to average Chinese people, Westerners more typically value rational thinking and reject superstition.

And yet I do not deny a human universal in desiring to know the future. In Canada, according to a news report, when the future seems unpredictable and when people are "at their wit's end", those who are usually skeptical may seek psychic guidance, especially when "their job securities and retirement savings are disappearing" (TorStar 2008). I want to emphasize that the degree of the engagement in divination of the entire population differs cross-culturally. As I observed in previous fieldwork (2012), the divination industry in the PRC is far more prosperous than the 'psychic reading' business in Canada. The national obsession with luck and fate, which is "a distinguishing characteristic of Chinese culture" (Sangren 2012: 117), has boosted the divination industry, and formed the 'economy of luck and fate'. In the alley south of the Lama Temple in Beijing, there are I-Ching and Feng Shui consultation offices on both sides of the alley. According to one I-Ching expert, who was running his own fortunetelling business in that alley and whom I interviewed in 2009, most of his clients were young people in their twenties or thirties. He charged about $\$ 18$ for a reading, while more advanced I-Ching experts' rates could be up to $\$ 400$. While most of his female clients ask for a reading about their relationship or marriage, men are usually more concerned about the prospect of their career, business, and investment.

As for high school teenagers, who can barely afford a reading, they are likely to turn to the pen spirit, since it is simple and cost-free. As some of my interviewees have informed me, the popular horror films about the pen spirit have reinforced their belief in spirits, for they think that the cinematic representation may be a true reflection of reality. Many of them have no doubts about the accuracy of the spirit's response. Leo, one of my informants in Beijing, in his early twenties, told me during a lengthy interview that he and his pals had increasingly believed in the accuracy of the pen spirit's response. He said, "I'm more serious about [the pen spirit] than ever, as an answer I got [from the pen spirit] in 2011 has been validated this year [2015]." The 'answer', according to him, was a prediction that within the next five years following 2011 , he would 


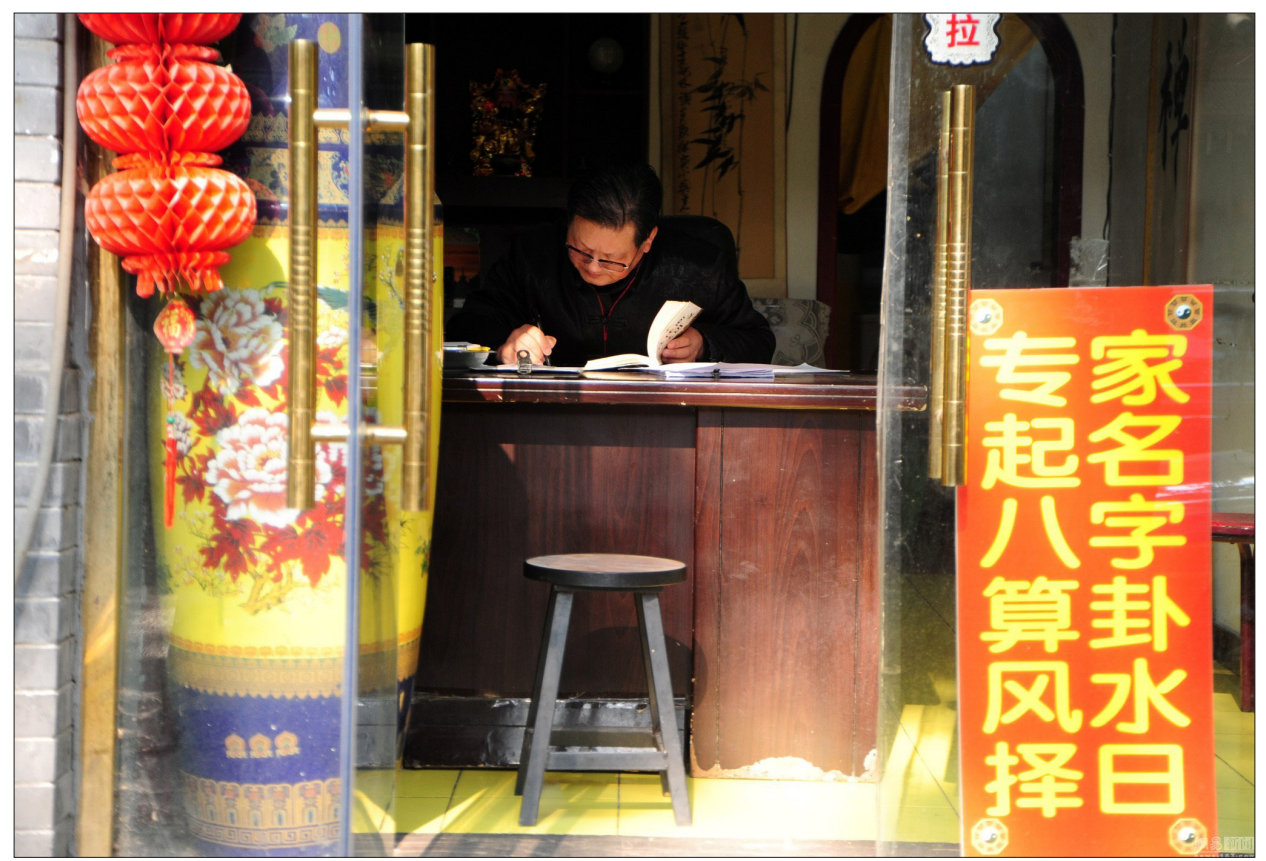

Figure 6. Fortune-telling street in Beijing.

Photograph credit: Beijing Times, November 3, 2015.

not be able to go abroad to study. After several unsuccessful attempts between 2011 and 2015, he finally secured sufficient funding for overseas education in October 2015, and was very likely to study at a college in Canada in 2016. He added, "The pen spirit is not always bullshit. That's why we love pen spirit movies." He also believed that most of his peers believed in pre-determined destiny more than in free will.

To investigate the divination culture in China, I would first look at the discursive production on fate and destiny in the Chinese language. Before the Buddhist teaching of karma or cause and effect and dependent origination were widely taken over by the Chinese, Chinese philosophers had reverenced fate as "the order of Heaven" (Schwartz 2000: 149), which should be understood as an early concept of pre-determinism, rather than fatalism. Thus, Confucian philosophers believe that, as the command of the deity of Heaven, fate cannot be altered or controlled (ibid.: 136-149). The Confucian thought has long recognized the impossibility of controlling certain aspects in destiny, such as fame, ranks, material wealth, and life expectancy. As a result, the Chinese language has accumulated over the centuries a rich collection of expressions 
around fate and destiny, including such idioms as “生死有命, 富, 在天” (To live or to die is destined; riches and honors depend on heaven); “一, 一啄，莫非前 定” (Every bite and every sip are preordained); and “穷通有定” (Success and failure are destined). With Buddhist doctrine widely accepted by the Chinese elite, the concept of fatalism gradually integrated into the Chinese indigenous thought on destiny, becoming an integral part of the collective unconscious of the Chinese. The teaching of karma does not only acknowledge the predeterminedness of one's destiny, but also believes that one's current status is the outcome of previously accomplished deeds, especially from past lives, and hence, the Chinese Buddhist proverb, “欲知前世因，今生受者是” (If you want to know your past, look into your present conditions). Ironically, while the original teaching of karma is meant to teach the Buddha's followers to be more proactive for self-improvement, by taking action to revise the cause in order to avoid or alter any negative effects, it has been interpreted and perceived by many as the negation of free will in all circumstances. As I have observed, a non-doing attitude to the material world is pervasive among lay Buddhists in China, which is often interpreted as a habitual acceptance of whatever situation the subject is currently in and whatever fate comes along.

As for China in general, it is ideologically, in terms of the core belief system in mainstream society, primarily an officially atheist country but it has still a long-lasting Buddhist culture integrated with the indigenous Daoism and Confucianism, which are marginalized and regulated under the Communist rule. During the Cultural Revolution (1966-1976) ${ }^{6}$, these religions along with Christianity were banned, as they were classified as part of the 'Four Olds' with feudal or bourgeois harm. In present-day mainland China, among other religions, Buddhism is not only revived but also thriving, while the revival started as early as in the modern Buddhist movement in Republican China (Wang 2013: 3-5). This means that though Buddhism was suppressed for a short period of time under the Ultra Leftist ideological regulation, it has not been eradicated from the collective memory of the people. Modern Chinese Buddhists, however, "engage in dialogues with materialism, idealism, Marxism, and other philosophical schools from the West" (ibid.: 5). The Buddhist doctrines integrated with secular values have established a new dichotomous belief: on the one hand, Chinese lay Buddhists (or simply Buddhist ritual practitioners) have accepted pre-determinism and/or fatalism as one major concept in Buddhist doctrines and the core of their personal belief system; on the other hand, the attachment to materialism, capitalism, and consumerism, which results in secular pursuits and/or engagement in divination, is suggestive of an adherence to 'doing' rather than 'non-doing', with an instinctual resistance to the pre-determined. This typical attitude is different from both free will and fatalism, in that it is seeking 
a short-cut to securing the expected and preferred trajectory of one's destiny. As a matter of fact, the popularity of mediumship such as the pen spirit or dish spirit among Chinese youth reflects that attitude in a larger picture - while the players believe that their future is pre-determined, they hope to know about the outcome of their acts in advance, in order to alter this outcome or the process leading to it. This appears particularly strong when the future seems out of reach, even though they may as well realize that there is no realistic meaning whatsoever in whether the pre-knowledge is accurate or not. As indicated in the interviews, the obsession with divination and mediumship reveals a widespread discontent about current societal and personal status quo, especially insecurities and fears generated by the vulnerability and unpredictability of employment and social security system. Social problems in contemporary Chinese society, which include "corruption, land grabs, income inequality, quality of life, and cost of living issues, local government debt, and an expanding urban-rural divide", have increased to "the point of crisis" (Sullivan 2014: 10-13). And yet, voices that address concerns and criticism are suppressed, while no realistic resolutions have met expectations year after year.

\section{THE TRANSFORMING SOCIETY AND FAITH IN MEDIUMSHIP IN CONTEMPORARY CHINA: SOME CASE ANALYSES}

Particularly the young generation born in the 1990s face unprecedented pressure caused by increasingly expensive housing, intense competition in university admissions and academic performance as well as in the job market. One of my young interviewees by the name of Lucy Guo tells me:

I have been job-hopping all the time these past two years. It's not because I want to change my job; it's because no job can keep me for more than half a year. Too many have been laid off for no reasons. Oftentimes when you are rushing to work you get a phone call telling you that you don't have to come to work anymore. Too bad we don't have employment insurance, which means once you are laid off, you will have to look for another job before you need to pay your next month's rent. This is Beijing. Take it or leave it. No one must hire you, as there are way too many talented folks in this city.

Lucy is a fan of mediumship. She particularly likes drawing oracles online, though occasionally she plays the dish spirit with her pals. For the past year, she has tried to 'channel' the spirits into using a smartphone application more 
than fifty times. Whenever she is invited to a job interview, she will draw an oracle to see how the interview will go. She says, "If the oracle is negative, then probably I won't go [to the job interview], for it will be a waste of time, energy, and emotions." This attitude is not uncommon among individuals of her age in the PRC. Another interviewee by the name of William Mao, however, is more concerned about his father's health. As the only child of the family and a member of the $4+2+1$ family structure (parents and parents-in-law, husband and wife, and their only child) due to the one child policy, he has an overwhelming financial burden. His personal narrative is typical:

These days everyone is talking about the old age pension scheme and the medical care system, but in the small village where I grew up, my parents and my wife's parents basically have nothing. My parents have poor health and seriously, if they become ill, we will have to spend all our savings. We can't rely on anyone else. Nor should we expect the government of the county to do anything for us. All we can do is to pray that nothing unfortunate will happen to us.

A firm believer in the supernatural and a fan of the supernatural in folklore, sometimes he is involved in different types of mediumship for a reading for himself and his entire family, including but not limited to the pen spirit, I-Ching consultation, and psychic séances. His case is not uncommon either, among the many interviews that I have conducted, since a lack of a well-funded social security system contributes to the widespread insecure feeling of the large group of low-to-medium income civilians.

Kaiwen Cao is a young actor who is well connected with psychic mediums, Tibetan lamas, and fortune-tellers in Beijing. He himself is also an occasional medium for pleasure, and sounds like an expert when talking about the pen spirit. His friends have informed me that sometimes he is amazingly accurate in his reading in a mediumistic state. During the interview I asked him to give me a reading and I can assure that much of his reading on my current situation made a great deal of sense (it should be added that he was aware of many details of my life already before and therefore his success was more or less granted). In recent years, he has been involved not only in the pen spirit and dish spirit, but also in the family constellations technique, which he says is extremely powerful in "developing one's potential of rediscovering the unknown past and foreseeing one's future". He interprets it as a new kind of mediumship. He informed me that there is a large family constellation community in Beijing, on which I have yet to conduct further research. When I asked him why he was so passionate about the supernatural, he said the following: 
People say no pain, no gain, and hard work pays off, but in the entertainment circle it is always luck that matters. It does seem like rolling a dice or buying lottery tickets. There are many talented actors and singers out there, but only few can become stars. It's not because they are talented, but because they have the perfect timing, and they meet the right person in the right place and at the right time. There may be hundreds or even thousands of actors auditioning for a leading role in a blockbuster, but only one will be picked. Do you think the selection is 100\% fair? No! I have great training, a university degree, and great looks, but luck has seldom befallen me. Other than a male lead and a number of supporting roles and extras, I have never had any good luck. I know lots of actors turn to mediums for help because they are not sure about where they are getting at, and the future is totally unpredictable.

The glamour industry mentioned in this text may be perceived as an epitome of society at large. Firstly, the interest in the supernatural reflects an increasing fear of the instability, unpredictability, and insecurities of personal and society's future associated with economic, social, and institutional change, as the PRC - the least religious country in the world according to Gallop International (2015) - is experiencing a crisis of faith after the communist ideology collapsed, which is believed by Liu Peng of the Chinese Academy of Social Sciences to be the result of "rapid economic growth" and the absence in the PRC of a "shared belief system" (D'avolio 2014). In 2011, the CPC-run newspaper People's Daily warned Beijing about the popular crisis of faith among its people, which may threaten and jeopardize the harmony and stability of society and the state's power. Secondly, the more rule of man is executed within the institutional and societal systems, the more unpredictability and insecurities an individual may feel, and thus, he or she will more likely turn to the supernatural for solace. In the glamour industry, for example, luck oftentimes plays a key role in determining one's trajectory, and for that reason, individuals such as Kaiwen firmly believe that God plays dice, and may get involved in divination and mediumship for guidance. Yet my most recent phone interview with Kaiwen in October 2015 indicated a dramatic turning point, as he informed me of his reaffirmed discovery through aging: turning to the supernatural is useless, as the origin of suffering lies in placing oneself in endless comparisons with one's peers in an unfair, man-ruled social competition, and it needs to be removed as much as possible. 


\section{CONCLUSION}

With film being the dominant medium for transmitting cultural beliefs, divination, and mediumship, which used to be common folkloric motifs in the past but are now presented as filmic folklore in popular horror films, it reflects contemporary belief trends consistent with the changing social context. Although the ideological regime in mainland China has been predominated by materialistic atheism, the revival of religions and supernatural rituals, which were perceived as feudal superstition during the Cultural Revolution, is the outcome of the crash of the Maoist and Communist faith, which has occurred during the social, economic, and institutional transformation since the establishment of the market economy. Besides, that revival also indicates a common feeling of insecurities in the population with regard to personal and familial future and the social security system. The popularity of the cinematic representation of the supernatural is not accidental; rather, it reflects the common attitude among the civilians, and culturally embodies a rich source of referential particularities and discourses of luck and fate, which preserve fragments of real data for the individuals.

\section{NOTES}

1 See more at http://yule.sohu.com/20120627/n346632159.shtml, last accessed on April 27, 2016.

2 The interviewees were selected during the course of writing Gai Ming (Change Destiny) (《改命》) (Beijing: New World Press, 2012), and were categorized into three groups. The first group contained friends, relatives, and associates, who claimed that they had experience with divination. The second group consisted of readers of my previous book, Ci Chang (Vibrations) ( 《磁场》) (Beijing: New World Press, 2010). The third group included some of the followers of my sina blog, who had demonstrated interest in the occult and who had exchanged views with me on divination and mediumship. In this article, I have only cited three typical interviews.

3 With a long history in Chinese folk religion, fuji (扶乩) is a Chinese Daoist ritual of 'spirit writing', where practitioners use a suspended sieve or tray to guide a stick to write Chinese characters in sand or incense ashes. It became popular during the Song Dynasty (960-1279), flourished during the Ming Dynasty (1368-1644), and was prohibited during the Qing Dynasty (1644-1912). Currently, it is practiced at Daoist temples in Taiwan, Hong Kong, and in mainland China. 
4 A dominant concept in traditional Chinese philosophy, yin and yang represent the two opposite and yet complimentary and interconnected principles of nature. The Five Elements - Wood, Fire, Earth, Metal, and Water - constitute a fivefold conceptual scheme abstracting from natural phenomena an order of mutual generation and mutual overcoming sequences.

5 In 2012, when I conducted research on the history of the Ouija board, I found various versions regarding its inception. Although as a Daoist ritual, fuji is much older than the Ouija board, and pen spirit and dish spirit games are highly similar to the Ouija board, I have not found abundantly sufficient evidence to support the assumption that there may have been an early East-West communication on mediumship. In fact, during the Cultural Revolution, when the PRC was closed to the outside world, pen spirit and dish spirit games had already become very popular, especially in the rural areas, but soon they were condemned and banned by the government as feudal superstition.

6 The Cultural Revolution was a social-political movement in the PRC from 1966 to 1976, led by Mao Zedong, then Chairman of the Communist Party of China. While the stated goal was to protect communist ideology from capitalism and feudalism, it brought a national disaster to the country politically, economically, and socially. 


\section{INTERVIEWS}

(Fieldwork Materials from Bao 2012)

Cao, Kaiwen: April 2012, April-May 2014, October 2015

Guo, Lucy: April 2012, April 2014, 2015

Mao, William: April 2012, April 2014

Lin, Leo: April 2012, April 2014

\section{REFERENCES}

Bao, Huai 2012. Gai Ming. [Change Destiny.] Beijing: New World Press.

Brunvand, Jan Harold (ed.) 1998 [1996]. American Folklore: An Encyclopedia. London \& New York: Routledge.

Clart, Philip 2003. Moral Mediums: Spirit-Writing and the Cultural Construction of Chinese Spirit-Mediumship. Ethnologies, Vol. 25, No. 1, pp. 153-189. http://dx.doi. org/10.7202/007129ar.

D'avolio, Lauren 2014. China's Crisis of Faith, Result of Rapid Economic Growth Divorced from Underlying Theology. The Gospel Herald, September 16. Available at http:// www.gospelherald.com/articles/52559/20140916/chinas-crisis-of-faith.htm, last accessed on April 27, 2016.

Eberhard, Wolfram 1966. Fatalism in the Life of the Common Man in Non-Communist China. Anthropological Quarterly. Special Issue. Fatalism in Asia: Old Myths and New Realities, Vol. 39, No. 3, pp. 148-160. http://dx.doi.org/10.2307/3316800.

Gallop International 2015 = Losing Our Religion? Two Thirds of People Still Claim to Be Religious. Worldwide Independent Network of Market Research, April 13. Available at http://www.wingia.com/web/files/news/290/file/290.pdf, last accessed on April 27, 2016.

Gauchou, Hélène L. \& Rensink, Ronald A. \& Fels, Sidney 2012. Expression of Nonconscious Knowledge via Ideomotor Actions. Consciousness and Cognition, Vol. 21, No. 2, pp. 976-982. http://dx.doi.org/10.1016/j.concog.2012.01.016.

Koven, Mikel J. 2003. Folklore Studies and Popular Film and Television: A Necessary Critical Survey. The Journal of American Folklore, Vol. 116, No. 460, pp. 176-195. http://dx.doi.org/10.1353/jaf.2003.0027.

Ma, Kevin 2014. Horror Film Franchise Files China Lawsuit. Film Business Asia, May 9. Available at http://www.filmbiz.asia/news/horror-film-franchise-fileschina-lawsuit, last accessed on April 26, 2016.

Sangren, P. Steven 2012. Fate, Agency, and the Economy of Desire in Chinese Ritual and Society. Social Analysis, Vol. 56, No. 2, pp. 117-135. http://dx.doi.org/10.3167/ sa.2012.560209.

Schwartz, Benjamin 2000. Kongzi de zongjiao cengmian he ming de gainian. [The Religiousness of Confucianism and the Concept of "Fate".] Trans. by Lin Tongqi. Shiji zhi jiao de zongjiao yu zongjiao xue yanjiu. [Religions at the Turn of the Century and the Study of Religion.] Hubei: Hubei People's Press, pp. 136-149. 
Sullivan, Jonathan 2014. China. Political Insight, Vol. 5, No. 1, pp. 10-13. http://dx.doi. org/10.1111/2041-9066.12041.

TorStar 2008 = Fortunes Turn for Some. TorStar News Service. Metro Toronto (frontpage), December 23. Available at http://www.deborahlouiselevin.com/images/media/ Metro-Dec2008.jpg, last accessed on April 27, 2016.

Wang, Q. Edward 2013. Buddhism in Modern China. Chinese Studies in History, Vol. 46, No. 3, pp. 3-6. http://dx.doi.org/10.2753/CSH0009-4633460300.

Wei-pang, Chao 1942. The Origin and Growth of the Fu Chi. Folklore Studies, Vol. 1, pp. 9-27. http://dx.doi.org/10.2307/3182924.

Zhang, Juwen 2005. Filmic Folklore and Chinese Cultural Identity. Western Folklore, Vol. 64, Nos. 3-4, pp. 263-280. Available at https://www.jstor.org/stable/i25474744, last accessed on April 27, 2016. 